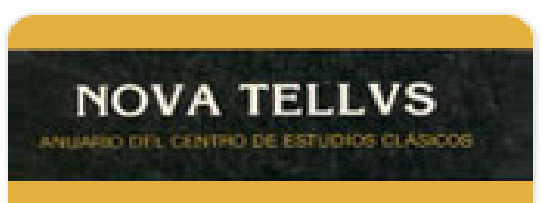

Nova Tellus

ISSN: 0185-3058

novatelu@servidor.unam.mx

Centro de Estudios Clásicos

México

SALLES, Ricardo

La teoría estoica de los sofismas

Nova Tellus, vol. 28, núm. 2, 2010, pp. 145-179

Centro de Estudios Clásicos

Distrito Federal, México

Disponible en: http://www.redalyc.org/articulo.oa?id=59120919006

- Cómo citar el artículo

Número completo

- Más información del artículo

- Página de la revista en redalyc.org

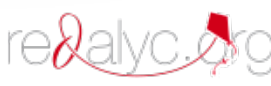

Sistema de Información Científica

Red de Revistas Científicas de América Latina, el Caribe, España y Portugal Proyecto académico sin fines de lucro, desarrollado bajo la iniciativa de acceso abierto 


\title{
La teoría estoica de los sofismas
}

\author{
Ricardo SALLES \\ Universidad Nacional Autónoma de México \\ rsalles@unam.mx
}

\begin{abstract}
RESUMEN: Este trabajo estudia las principales fuentes antiguas sobre la teoría que emplearon los estoicos para intentar dilucidar la naturaleza de los sofismas. Para esto, se ofrece un análisis detallado de la distinción trazada por ellos entre los sofismas que dependen del "sonido vocal" y aquellos que dependen de "estados de

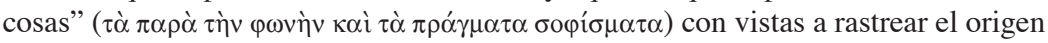
posible de su teoría y algunas diferencias que parece haber entre la manera en que los estoicos lidian con ciertos sofismas como "el Mentiroso" y "el Montón”, y la manera en que lo hacen algunos filósofos modernos de la lógica.
\end{abstract}

\section{The Stoic Theory of Sophisms}

ABSTRACT: This paper offers an analysis of the main ancient sources for the theory employed by the Stoics to shed light upon the nature of sophisms. To do so, a close analysis is given of the distinction the Stoics draw between sophisms that depend

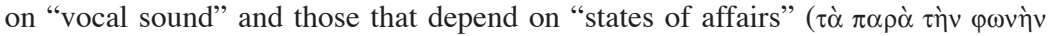

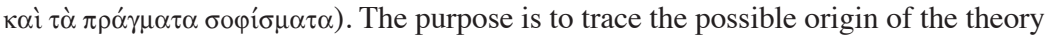
and certain differences there seems to be between how the Stoics handle certain sophisms such as "the Liar" and "the Sorites", and the way in which some modern logicians do it.

PALABRAS ClAVE: Paradojas, falacias, filosofía de la lógica, epistemología KEYWORDS: Paradoxes, fallacies, philosophy of logic, epistemology.

RECEPCIÓN: 21 de junio de 2010.

ACEPTACIÓN: 17 de agosto de 2010. 



\title{
La teoría estoica de los sofismas ${ }^{1}$
}

\author{
Ricardo SALLES
}

En este trabajo me ocupo de un área poco estudiada de la doctrina de la argumentación de los estoicos antiguos: su teoría de los sofismas. Para ello, divido la exposición en tres partes. En la primera, me refiero a la definición general de sofisma que hallamos en las fuentes estoicas y de algunos de sus posibles antecedentes. En la segunda y la tercera, ofrezco un análisis de sus principales elementos. Según los estoicos, la primera división de los sofismas es entre los que "dependen del sonido vocal y los que dependen de los estados de cosas" ( $\tau \grave{\alpha} \pi \alpha \rho \grave{\alpha} \tau \grave{\eta} v$

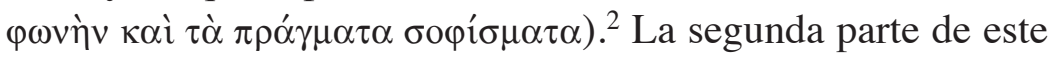
artículo se dedica a ofrecer una caracterización de esta primera categoría de sofismas y, en particular, del lugar que desempeña

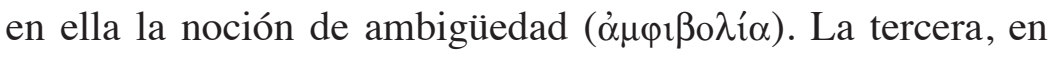
cambio, se ocupa de la segunda categoría. Entre los sofismas estoicos que dependen de los estados de cosas, hay dos clases

\footnotetext{
${ }^{1}$ Presenté la primera versión de este trabajo en diciembre de 2008 en el seminario de filosofía antigua del doctor Marcelo Boeri en la Universidad de los Andes, en Santigo de Chile. Quiero agradecer todos los comentarios recibidos en esa ocasión, los cuales me ayudaron a afinar mis argumentos. También estoy agradecido con el dictaminador anónimo de Nova Tellus, cuyas observaciones críticas me permitieron corregir varios errores. Cabe señalar que soy el único responsable de los errores que todavía pudieran encontrarse. La versión final de este artículo se realizó en el Institute for Advanced Study de Princeton gracias al fondo Willis F. Doney Membership Endowment y en el marco del proyecto CB2008-01 100539 de CONACYT.

${ }^{2}$ Cf. el primer texto citado (1a) en el Apéndice. En éste se citan in extenso las principales fuentes antiguas que emplearé aquí.
} 
que han cobrado fama en la filosofía de la lógica de hoy en día:

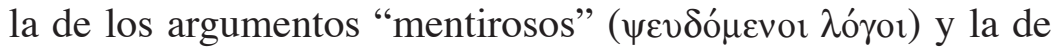

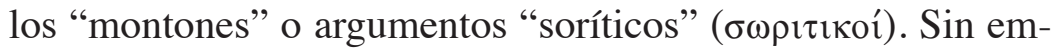
bargo, la postura estoica respecto de ellos no es del todo clara y, al estudiar cuidadosamente las fuentes, podemos percatarnos de que, hasta la fecha, ésta no ha sido correctamente entendida por los estudiosos de la teoría estoica de los sofismas. En particular, veremos que, al lidiar con los argumentos soríticos, los estoicos pretenden resolver un problema distinto del que ha preocupado a los filósofos modernos de la lógica que se han ocupado de esta clase de sofisma: mientras que éstos se preguntan por qué ciertos predicados y su negación - por ejemplo "calvo" y "no-calvo" - pueden a veces predicarse de un mismo objeto, los estoicos, al contrario, se preguntan por qué hay ciertos predicados tales que, a veces, ni ellos, ni su negación, - por ejemplo "mucho" y "no-mucho" - puede predicarse de un mismo objeto. Este segundo problema, pero no el primero, supone la existencia de objetos vagos, es decir, de objetos que son neutrales respecto de si satisfacen o no un cierto predicado. Esto ayuda a explicar por qué los estoicos, a diferencia de la mayoría de los filósofos modernos de la lógica, son realistas respecto de la vaguedad: ésta, entendida como una neutralidad respecto de ciertos predicados es una rasgo propio e intrínseco de ciertos objetos.

\section{1. ¿Qué es un sofisma?}

De acuerdo con el testimonio de Sexto Empírico en el texto $1 \mathrm{~b}$, para los estoicos un sofisma es un argumento falso ( $\psi \varepsilon v-$ $\delta$ '́s) y, conforme a lo que sabemos gracias al texto 1c, es falso aquel argumento cuyas premisas no son todas verdaderas o cuya conclusión no se sigue válidamente de sus premisas aunque éstas sean todas verdaderas (siendo verdaderos únicamente aquellos argumentos en los cuales la conclusión se sigue 
válidamente de las premisas y todas estas son verdaderas). ${ }^{3}$ Según 1b, los estoicos sostienen que la diferencia específica del sofisma al interior de la clase de los argumentos falsos radica en ser convincente pero engañoso ( $\delta \varepsilon \delta \circ \lambda \imath \varepsilon v \mu \varepsilon ́ v o v)$ de tal ma-

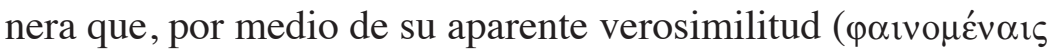
$\pi \imath \theta \alpha v o ́ \tau \eta \sigma v)$, se acepta su conclusión a pesar de que ésta es,

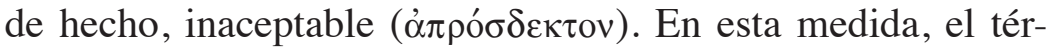
mino castellano "sofisma" que elegí para para referirme a los

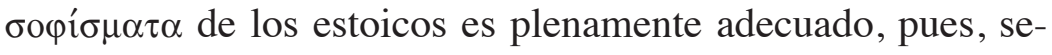
gún su definición, sofisma es precisamente una "razón o argumento aparente con que se quiere defender o persuadir lo que es falso" (DRAE s.v. sofisma). También podría emplearse "paradoja" si seguimos la definición que adopta un estudioso reciente de este fenómeno: "esto es lo que llamo una paradoja: una conclusión aparentemente inaceptable derivada por medio de un razonamiento aparentemente aceptable de premisas aparentemente aceptables". Pero el término "sofisma" es, en

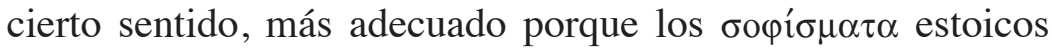
son argumentos cuyo propósito es engañar al adversario del hablante con vistas a vencerlo en la discusión, connotación que parece estar ausente del término "paradoja". En este senti-

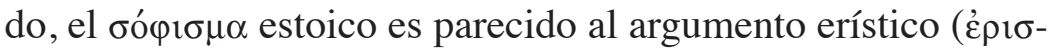
$\tau \imath \kappa o ́ \varsigma ~ \sigma v \lambda \lambda o \gamma \imath \sigma \mu o ́ \varsigma)$ definido en los Tópicos y las Refutaciones

${ }^{3}$ Cf. Mates, 1953, p. 60: "A true argument is an argument which is valid and which has true premisses; a false argument is either invalid or [is valid but] has a false premiss". Por ello, el concepto estoico de argumento verdadero no tiene la misma extensión que el concepto de argumento válido de la lógica moderna, pues, según este último, todo argumento dotado de premisas falsas es válido en la medida en que, de acuerdo con este concepto, de una falsedad puede inferirse válidamente cualquier verdad o cualquier falsedad (siendo el único argumento inválido aquel cuya conclusión es falsa pero la conjunción de todas sus premisas es verdadera).

${ }^{4}$ Cf. Sainsbury, 2009, p. 1. Para la diferencia, dentro del estoicismo, entre sofismas y paradojas ( $\pi \alpha \rho \alpha ́ \delta$ o $\alpha$ ), cf. SVF 3.544 y 599 (cf. Cicerón, Paradoxa Stoicorum 4-5 y los distintos ejemplos de "paradojas" desarrollados en estas secciones del tratado). Tal como se presentan en estos textos, las $\pi \alpha \rho \alpha ́ \delta o \xi \alpha$ son tesis más que argumentos. 
Sofísticas de Aristóteles (cf. 100b23-101a4 y 165b7-8 respectivamente) y, aún antes, en el Eutidemo de Platón (cf. 278a7c2). ${ }^{5}$ Esto podría tal vez indicar que el estudio de los sofismas por parte de los estoicos forma parte de una tradición de la cual tanto Platón como Aristóteles son claras expresiones.

De hecho, si nos preguntamos de dónde provienen los sofismas estoicos, parece ser preciso postular su origen en algún autor que haya podido, a la vez, influenciar las Refutaciones Sofísticas y el Eutidemo. La necesidad de un origen común se debe a los fuertes parecidos que hay entre varios de ellos, por ejemplo, (a) entre los sofismas estoicos citados en el texto 3 y los citados por Platón en 297e-298a (si uno es el padre de Sócrates y otro el padre de Patroclo, el primero es distinto de un padre y, por consiguiente, no es un padre) y en 298d-e (si este perro es tuyo y si este perro es un padre, este perro es padre tuyo), (b) entre los sofismas que los estoicos estudian en los textos 9 y 10 y los que Aristóteles (en 165a10-20) y Platón (en 275d-276c y 276d-277) atribuyen al uso equívoco de términos, y (c) entre los sofismas que, según los estoicos en 9, se dan por culpa de ambigüedades sintácticas y los que Platón menciona en 300a y 301c. ¿Cuál pudo entonces haber sido el origen común de todos ellos? Un origen que algunos especialistas han considerado como posible es el personaje histórico Eutidemo, ateniense de fines del siglo v a. C. ${ }^{6}$ Este Eutidemo y su escuela habrían sido la fuente de inspiración común de Platón y Aristóteles en estas obras y, directa o indirectamente, de los sofismas estoicos. Sin embargo, como también vere-

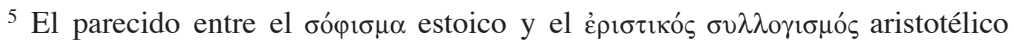
se debe a que ambos pretenden engañar al oyente. De acuerdo con Top. 100b23101a4, por ejemplo, el argumento erístico es aquel cuyas premisas parecen ser todas verdaderas, pero en realidad no lo son, o cuya conclusión parece seguirse válidamente de sus premisas, pero en realidad no lo hace, siendo que esta apariencia es engañosa pues la falsedad de los argumentos erísticos sólo es evidente para

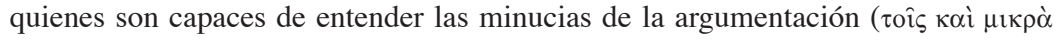

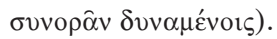

${ }^{6}$ Cf. Praechter, 1932, y Canto, 1989, pp. 27-28.
} 
mos, hay sofismas cuya formulación debemos principalmente a los estoicos mismos. Entre ellos, cabe destacar "el Mentiroso" y "el Montón". 7

En las fuentes estoicas, encontramos una clasificación sistemática de los sofismas. Ésta aparece en 1a: los sofismas se dividen en aquellos que dependen del sonido vocal y aquellos

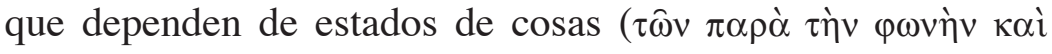

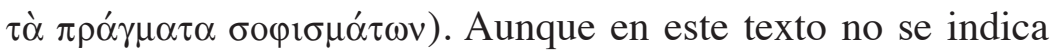
cuál es el criterio que rige esta división, es posible que corresponda grosso modo a la clasificación básica que propone Aristóteles en $S E$ de los silogismos erísticos entre aquellos que acompañan a la expresión linguiística y aquellos ajenos a

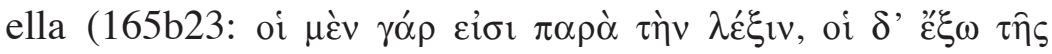
$\left.\lambda \varepsilon^{\prime} \xi_{\varepsilon \omega \varsigma}\right)$. En el siguiente apartado, nos ocupamos de los que dependen del sonido vocal y, en el tercero, de los que dependen de los estados de cosas.

\section{Los sofismas que dependen del sonido vocal}

Es probable que en la categoría estoica de los sofismas que

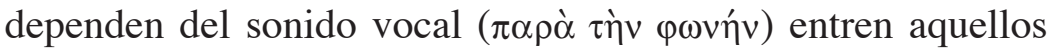
que se deben al uso equívoco de ciertas expresiones, es decir, aquellos que engañan al oyente en virtud de usar una misma expresión con significados distintos. ${ }^{8}$ Un ejemplo serían "los silogismos que descansan en una homonimia" descritos en el texto 10. En ellos, parece obtenerse la conclusión en virtud

\footnotetext{
${ }^{7}$ A diferencia de los anteriores, estos sofismas no tienen una correspondencia clara en Platón y Aristóteles y, al menos uno de ellos, "el Mentiroso", junto con "el Cornudo" en 3 y "el Encapuchado" en 2, parece tener su origen en Eubúlides, socrático menor sucesor de Euclides de Megara en la dirección de la escuela dialéctica. Cf. Diógenes Laercio 2. 108. Otro antecedente posible del sofisma del "Encapuchado" se encuentra en Aristóteles. Cf. Aristóteles, Refutaciones Sofísticas (SE) 179a33-b6 y Anon., en SE 125, 13-18. Véase también Atherton, 1993, p. 410 n. 3.

${ }^{8}$ Cf. Atherton, 1993, p. 415, y Barnes-Bobzien-Mignucci, 1999, p. 158.
} 
del uso equívoco del término "masculino" (ỏv $\delta \rho \varepsilon i ̂ \varsigma)$ pues, como explica el texto y como veremos más adelante, este término tiene en griego al menos dos significados claramente distintos.

La homonimia, sin embargo, es sólo un caso, entre muchos otros posibles, en que puede darse el uso equívoco de expresiones. En verdad, hay casos de uso equívoco de expresiones que no se deben a una homonimia. La homonimia atañe a la pluralidad de significados de una palabra, pero hay expresiones lingüísticas que, no siendo palabras, pueden tener, ellas mismas, múltiples significados. Tal es el caso de ciertas oraciones que examinaremos más adelante en este apartado. En este caso, explica el texto 9, la oración completa tiene una multiplicidad de significados en virtud meramente de su sintaxis, sin que ninguna de las palabras que figuran en ella tenga, ella misma, más de un significado. De este modo, según 9, la homonimia es un tipo de ambigüedad ( $\alpha \mu \varphi \imath \beta o \lambda i ́ \alpha)$, pero hay, cuando menos, ochos tipos distintos de ambigüedad, siendo la homonimia sólo una de ellas (las otras siete, como lo sugiere el texto 9, serían sintácticas).

En resumen, los sofismas que dependen del sonido vocal entrañan una ambigüedad - de palabra o de sintaxis - en virtud de la cual la expresión ambigua puede emplearse equívocamente. Asimismo, al haber ocho tipos de ambigüedad, habría al menos ocho tipos de sofismas que dependen del sonido vocal. Ahora bien ¿es la equivocidad (de palabra o de sintaxis) una condición suficiente, o también una condición necesaria, para que, según los estoicos, un argumento sea un sofisma que depende del sonido vocal? Salvo en el caso del texto 1a, en que se sugiere que existen anomalías lingüísticas distintas de la ambigüedad que podrían generar sofismas que dependen del sonido vocal, en las fuentes no hay una respuesta a esta pregunta, pero no se menciona ningún fenómeno lingüístico distinto de la equivocidad que pudiera dar origen a un sofisma que dependa del sonido vocal. En particular, 
los sofismas debidos a la vaguedad (como, por ejemplo los "[sofismas] montones"), no pertenecen al ámbito de los que dependen del sonido vocal, sino al de los que dependen de estados de cosas extra-lingüísticos. ${ }^{9}$ A ellos regresaremos en el siguiente apartado.

En la clase de los sofismas que dependen del sonido vocal, la noción de ambigüedad - $\alpha \mu \varphi \imath \beta o \lambda i ́ \alpha-$ merece especial atención. Como vimos, en efecto, esta clase de sofismas depende del uso equívoco de expresiones y éste, a su vez, de la ambigüedad de dichas expresiones. Para citar un ejemplo que encontramos en 10: "El abrigo es masculino, masculino es animoso, por consiguiente el abrigo es animoso". Es un sofisma debido a una homonimia (o $\mu \omega v \iota \mu$ í $\alpha)$ que afecta el término "masculino" ( $\alpha \nu \delta \rho \varepsilon \hat{i} о \varsigma)$ cuando no se especifica si el hablante se refiere a lo varonil, en cuyo caso el término puede aplicarse a objetos inanimados, como los abrigos, o a lo animoso ( $\varepsilon$ vi- $^{-}$ $\psi v \chi \circ \varsigma$ ), en cuyo caso sólo puede aplicarse a personas. Gracias a esta ambigüedad, el argumento anterior usa "masculino" para inferir, a partir de premisas aparentemente verdaderas, una conclusión inaceptable como El abrigo es animoso. La ambigüedad opera en la segunda premisa - "masculino es animoso" - pues si bien es verdadera en el caso de personas, es falsa en el caso de cosas inanimadas, como los abrigos, pues "animoso" no es un atributo de abrigos y, por ende, no puede aplicarse a ellos. La solución del sofisma consiste en poner a descubierto este hecho, con lo cual el interlocutor no se ve realmente obligado a aceptar esta conclusión. En efecto, la conclusión se sigue de las premisas sólo si la segunda de ellas dice algo equivalente a masculino aplicado a abrigos es animoso. Pero, en ese caso, la premisa sería falsa. En cambio, si la segunda premisa dijera algo equivalente a masculino aplicado a personas es animoso, la conclusión no se seguiría de las premisas. Por lo tanto, no hay una interpretación de

${ }^{9}$ Véanse muy particularmente los textos 1 a y 7. 
la segunda premisa tal que el interlocutor del hablante tenga realmente que aceptar la conclusión, pues para verse obligado a tal cosa, la conclusión tendría que seguirse de las premisas $\mathrm{y}$, a la vez, las premisas tendrían que ser verdaderas.

La definición general de ambigüedad - $\alpha \mu \varphi \imath \beta$ en el texto 8: es ambigua aquella expresión que significa dos o más estados de cosas ( $\pi \rho \alpha ́ \gamma \mu \alpha \tau \alpha)$ es decir, dos o más decibles ( $\lambda \varepsilon \kappa \tau \alpha$ ) siempre y cuando ella signifique ambos estados de cosas "linguíística y estrictamente y de acuerdo con el mismo

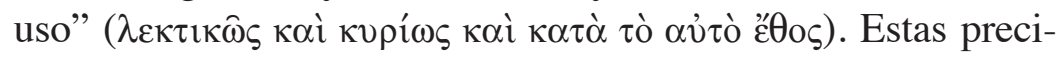
siones respecto del modo en que la expresión ambigüa debe de significar han sido objeto de un análisis detallado en la literatura reciente sobre este tema y no regresaré a ellas en este trabajo. ${ }^{10}$ Por ahora, cabe notar que, según 8 , los portadores de ambigüedad son, de forma genérica, las expresiones lingüísticas $\left(\lambda \dot{c}^{\prime} \xi \varepsilon 1 \varsigma\right)$ y no únicamente los sonidos vocales ( $\left.\varphi \omega \vee \alpha i ́\right)$, los cuales constituyen, en realidad, sólo un tipo de expresión lingüística. Esto implica que a los sofismas que dependen del

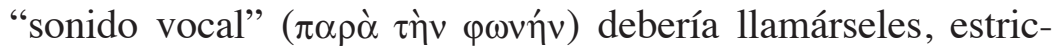
tamente, sofismas que dependen de la "expresión lingüística"

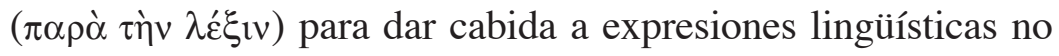
vocales. En cualquier caso, tanto $\lambda \varepsilon^{\prime} \xi$ iऽ como $\varphi \omega v \eta ́$ pueden referirse indistintamente a palabras sueltas $\mathrm{u}$ oraciones, lo cual implica que la definición que aparece en 8 se aplica tanto a la ambiguiedad de una palabra como a la ambigüedad sintáctica. Tal es el caso del ejemplo que aparece en el texto: la expresión

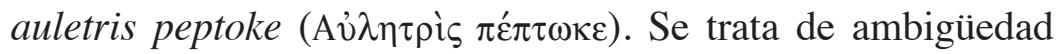
sintáctica porque la expresión puede significar que una casa tres veces se ha caído (aule $=$ casa, tris $=$ tres veces, peptoke= se ha caído) y, a la vez, que la flautista se ha caído (auletris= flautista). Esta ambigüedad sintáctica ha de haber sido particularmente evidente en el caso de la expresión escrita, pues, como

${ }^{10}$ Cf. Atherton, 1993, pp. 152-174; Salles, 2002, pp. 9-12, y 2005, pp. 100-103, y Boeri, 2003. 
era costumbre en la época clásica y helenística, las expresiones escritas aparecían en mayúsculas y, sobre todo, sin espacios ni

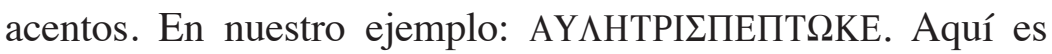
patente que no hay nada en la expresión misma que descarte uno de los significados, a diferencia de lo que ocurre si se escribe la expresión como aparece en los códices - A $v \lambda \eta \tau \rho i \varsigma$ $\pi \dot{\varepsilon} \pi \tau \omega \kappa \varepsilon-$ pues, en este caso, parece descartarse el significado una casa tres veces se ha caído en la medida en que Av̉ $\lambda \dot{y}$ y

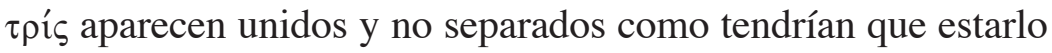
para poder dar ese significado. ${ }^{11}$ El texto 9 de Galeno pone de manifiesto este problema al dar como ejemplo de ambigüedad la expresión AY $\Lambda$ HTPI $\Sigma \Pi E \Sigma O Y \Sigma A$, la cual aparece en los códices sin espacios ni acentos. ${ }^{12} \mathrm{Si}$ observamos la lista de ocho ambigüedades que aparece en 9 podemos notar que varias de ellas, y no sólo AY $\Lambda$ HTPI $\Sigma \Pi E \Sigma O Y \Sigma A$, se ajustan a la definición de ambigüedad sintáctica que hallamos en 8. Para sólo tomar dos ejemplos, la sexta y la octava son casos claros de ello. ${ }^{13}$

\section{Los sofismas que dependen de estados de cosas}

Pasemos ahora a la clase de los sofismas que dependen de estados de cosas ( $\pi \alpha \rho \grave{\alpha} \tau \grave{\alpha} \pi \rho \alpha ́ \gamma \mu \alpha \tau \alpha)$. De acuerdo con 1a, esta

${ }^{11}$ Cf. Boeri, 2003, p. 187 n. 11.

${ }^{12}$ En este ejemplo, el verbo $\pi i ́ \pi \tau \omega$ aparece en participio aoristo mientras que, en el ejemplo anterior, aparecía en indicativo perfecto. Hasta donde puedo ver, esta diferencia no es importante. La principal diferencia es que en AY $\Lambda$ НР $\Sigma \Pi E \Sigma O Y \Sigma A$, la expresión en su conjunto aparece sin separaciones ni acentos. Esto pone de manifiesto la ambigüedad que, de otra forma, no puede apreciarse claramente, pues al dividirse y acentuarse las palabras, la expresión toma una morfología específica y parece admitir un solo significado.

${ }^{13}$ La existencia de ambigüedades así entendidas tiene consecuencias importantes tanto para la metafísica estoica y el tema de la individualización de los incorpóreos, así como para su física y, en concreto, para el problema de la diferenciación temporal de los ciclos cósmicos. Sobre el problema de la diferenciación de los ciclos cósmicos, cf. Barnes, 1978. Sobre cómo la teoría estoica de las ambigüedades puede ayudar a resolver ese problema, cf. Boeri, 2003, y Salles, 2002 y 2005. 
clase incluye una larga serie de sofismas que ya eran famosos en la época helenística:

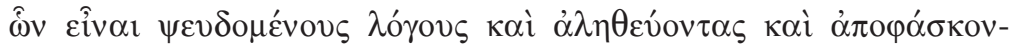

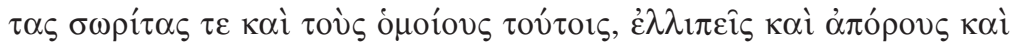

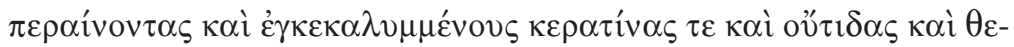
pí̧ovtas.

Entre estos sofismas se encuentran los argumentos "mentirosos", los que "dicen la verdad", los "que niegan", "los montones", así como los que se asemejan a ellos (los defectuosos, los aporéticos y los concluyentes), y asimismo "[los] encapuchados", "cornudos", "no-alguien" y "segadores".

La enumeración que aparece en el texto merece dos comentarios. El primero es que el uso de plurales puede significar que los estoicos lidiaron con varias versiones de cada uno de los sofismas que se mencionan, porque probablemente no existía una única formulación canónica de ninguno de ellos. ${ }^{14}$ El segundo comentario se refiere a la tripartición entre sofismas "defectuosos", "aporéticos" y "concluyentes". A primera vista, podría tratarse de tres clases específicas de sofismas que dependen de estados de cosas. Es decir, al igual que "los mentirosos", "los que dicen la verdad", "los que niegan", "los montones", "los encapuchados", "los cornudos", "los noalguien" y "los segadores", las tres clases que nos interesan compondrían la clase genérica de los que dependen de estados de cosas. Sin embargo, en un trabajo reciente, se ha sostenido que la tripartición defectuosos-aporéticos-concluyentes, constituye una división distinta e independiente. ${ }^{15}$ De acuerdo con esta lectura, habría, en verdad, dos clasificaciones estoicas de los sofismas que dependen de estados de cosas: una de ellas los dividiría en ocho (mentirosos, que dicen la verdad, que niegan, montones, encapuchados, cornudos, no-alguien y segadores)

\footnotetext{
${ }^{14}$ Al respecto, cf. Barnes-Bobzien-Mignucci, 1999, p. 158 n. 157.

15 Idem, 1999, p. 158.
} 
y la segunda, posterior a ésta, dividiría a estas ocho clases en defectuosos, aporéticos y concluyentes. El texto 7 está a favor de esta lectura: al clasificar "los encapuchados", "los montones", "los cornudos" y "los no-alguien" dentro de la clase de los aporéticos, este texto parece sugerir que los sofismas aporéticos son, en sí mismos, una clase que comprende a los encapuchados, los montones, los cornudos y los no-alguien. Sin embargo, contra esta lectura está 1a. Ahí los sofismas aporéticos se presentan como una clase alineada a la de "los encapuchados", "los montones", "los cornudos" y "los noalguien", es decir, como clases del mismo orden donde unas no comprenden a las otras, según lo supone la interpretación anterior. Esto indica la presencia de una tensión en las fuentes, probablemente insuperable, respecto de la clasificación estoica de los sofismas. En cualquier caso, muchos de ellos son joyas de la lógica filosófica y todavía hoy en día son objeto de análisis y debate por parte de filósofos del lenguage y de la lógica, en particular, "los Mentirosos" y "los Montones". ${ }^{16}$

La principal formulación de "los Mentirosos" proviene de Cicerón en el texto 4. Debido a una laguna textual importante, a la que me refiero en el Apéndice, es imposible conocer el significado exacto del texto. ${ }^{17}$ Pero es una posibilidad es: "si dices que mientes y en esto dices la verdad, mientes $<y$, si mientes, $>$ dices la verdad". Es decir, si digo "Miento" y lo que digo - la proposición Miento - es verdadero, entonces, si esta proposición se refiere a todo lo que digo, incluyéndola a ella, se sigue que estoy mintiendo y, por lo tanto, que lo que digo es falso. Pero si lo que digo es falso, es decir, si es falso que miento,

\footnotetext{
${ }^{16}$ Véanse por ejemplo Williamson, 1994; Beall, 2003 y 2007 y Sainsbury, 2009.

${ }^{17}$ En la traducción adoptamos la lectura de Mignucci: si te mentiri dicis idque verum dicis, mentiris <et, si mentiris,> verum dicis ("si dices que mientes y en esto dices la verdad, mientes $<y$, si mientes $>$, dices la verdad"). Para una defensa filosófica y filológica de esta lectura, cf. Mignucci, 1999, pp. 59-60. Para una discusión detallada de las distintas propuestas editoriales para colmar la laguna. Cf. Mignucci, 1999, pp. 56-62; Barnes-Bobzien-Mignucci, 1999, pp. 163-167, y Bobzien, 2002, pp. 221-222.
} 
entonces, dado que lo opuesto de mentir es decir la verdad, lo que digo es verdadero. En conclusión, al decir "Miento", si lo que digo es verdadero, lo que digo es falso y, si lo que digo es falso, lo que digo es verdadero. ${ }^{18}$ Según sabemos gracias Plutarco en 5, Crisipo adoptó una postura respecto de este sofisma según la cual es preciso (1) "negar que es falsa sin restricción una conjunción que se obtiene por medio de [pro-

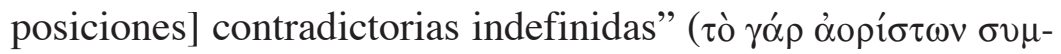

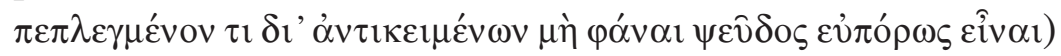
y (2) "afirmar que en ciertos argumentos que poseen premisas verdaderas y realizan una inferencia congruente, las contradictorias de sus conclusiones también son verdaderas" ( $\lambda$ ó

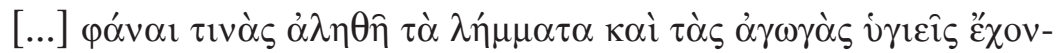

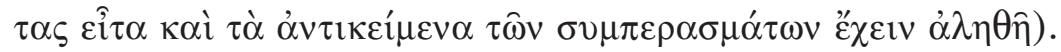
En (1), las dos proposiciones serían, en este caso, Miento y su contradictoria, Digo la verdad, y Crisipo habría afirmado que su conjunción no es falsa. En (2), Crisipo habría reconstruido el sofisma bajo la forma de un argumento congruente cuyas premisas implicarían la verdad tanto de su conclusión como de la contradictoria de su conclusión, lo cual equivale a decir, como en (1), que hay conjunciones no falsas de proposiciones contradictorias. Es difícil entender a partir de este testimonio de Plutarco cuál era exactamente la solución que Crisipo pretendía aportar al problema. Pero, según el testimonio de $\mathrm{Ci}$ -

18 Otras dos fuentes importantes sobre el sofisma del "Mentiroso" son los fragmentos de las Investigaciones Lógicas de Crisipo que aparecen en las columnas 9-21 de PHerc. 307 (fragmentos editados en SVF 2.298a y FDS 698), Gelio, Noctes Atticae 18.2.9-10 y Anon. in Sophist. Elench. 25.58, 29-33 tradicionalmente atribuido a Alejandro de Afrodisia. Cf. Mignucci, 1999, p. 1 nn. 1-6. Este sofisma tiene probablemente su origen en Eubúlides (Diógenes Laercio 7.108), sucesor de Euclides de Megara (cf. apartado 1 más arriba). Hay rastros de este sofisma en el

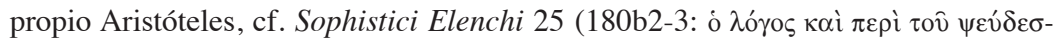

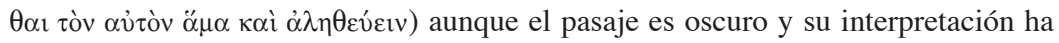
generado polémica. Cf. Mignucci, 1999, pp. 55-56. Para definir el género al que pertenece el sofisma mentiroso dentro de la lógica contemporánea, cf. cap. 5 de Sainsbury, 2009, y también Beal, 2003 y 2007. 
cerón en 4, su percepción del problema parece haber sido que éste sólo surge cuando se intenta atribuir un valor de verdad a estas proposiciones y que, por consiguiente, una solución al problema requiere no atribuirles ningún valor de verdad. Proposiciones como Miento serían, por lo tanto, una excepción al principio de bivalencia. ${ }^{19}$

A una conclusión similar puede llegarse respecto de la solución que parece haber propuesto Crisipo a "los Montones". Una de las principales formulaciones aparece en el texto 7: "no es el caso que dos sean pocos, pero que tres no lo sean, ni que éstos [lo sean] pero cuatro no lo sean, y así hasta llegar a diez. Sin embargo, dos son pocos, por consiguiente también lo son diez". ${ }^{20}$ En principio, la adopción por parte de los estoicos del principio de bivalencia los obliga a aceptar que la proposición $x$ son pocos tiene un valor de verdad determinado en cada una de las etapas del proceso, pues no puede carecer de uno en algún punto si es que efectivamente, como lo pide el principio

${ }^{19}$ Esta línea interpretativa ha sido propuesta y desarrollada en Mignucci, 1999, Barnes-Bobzien-Mignucci, 1999, pp. 168-169, y Bobzien, 2002, pp. 221-222. Si la interpretación es correcta, la solución estoica es distinta de la propuesta por los restringentes medievales, quienes argumentan que proposiciones como Miento son siempre falsas porque son autocontradictorias (tal es el caso de Guillermo de Ockham, cf. Spade, 1988) y, hasta cierto punto, distinta también de la propuesta por los cassantes, quienes argumentan que proposiciones como Miento no son proposiciones genuinas sino sinsentidos a los que no se puede atribuir un valor de verdad (tal es el caso del tratado anónimo del siglo XII De Insolubilibus, cf. De Rijk, 1966). Los estoicos referidos por Cicerón en el texto 4 no parecen adoptar la postura de los cassantes porque: (a) no afirman que estas proposiciones sean sinsentidos, sino sólo que son "inexplicables" (inexplicabilia) y, además, porque (b) Cicerón observa una tensión entre aceptar la definición de proposición - la cual dice que toda proposición debe de tener un valor de verdad - pero no atribuir un valor de verdad a algo como Miento, pues sólo puede haber tal tensión si Miento es considerado una proposición. Para una interpretación que identifica la postura estoica con la de los cassantes, cf. Alejandro de Afrodisia, en Top. 188, 19-28.

${ }^{20}$ Para otras versiones del sofisma, cf. Sexto Empírico AM 10.113-18 Cicerón, Acad. 2.93 y Galeno, Exp. Med. 16. 1-17.3. Véase también Plutarco, Comm. Not. 1084C-D (versión respecto de la cual Bobzien, 2002, p. 217 n. 3 y 227 n. 36 argumenta que no es del tipo sorites). 
de bivalencia, toda proposición es verdadera o falsa. Esto, sin embargo, implica que hay un punto exacto del proceso en que la proposición cambia de valor de verdad, a saber, cuando el valor de la variable $x$ deja de ser poco y pasa a ser mucho. Ahora bien, dado que existe tal punto, se sigue que la conclusión a la que pretende llegar el sofisma - "diez también son pocos" - es falsa: pues aunque no sepamos en qué punto de 1 a 10 dejó de haber pocos y empezó a haber muchos, sabemos, en virtud de la verdad del principio de bivalencia, que hubo tal punto. Ergo, no estamos obligados a aceptar esa conclusión y, con ello, se viene abajo el sofisma. Según esta interpretación la estrategia estoica puede calificarse de "epistemicista". La indeterminación que afecta el uso de predicados como Ser pocos no se debería a los objetos que satisfacen esos predicados, pues todo objeto o bien satisface ese predicado o bien no lo satisface (no hay objetos vagos), sino a nuestra falta de discernimiento: la causa de la vaguedad es una carencia de nuestro aparato epistemológico. Habría casos límite en que somos incapaces de determinar con claridad si un objeto dado satisface ese predicado o no.

Sin embargo, esta interpretación epistemicista de los estoicos, cuyo defensor más reciente es Timothy Williamson, ${ }^{21}$ se contrapone a una lectura no-epistemicista y de carácter más bien metafísico, desarrollada en todo detalle por Susanne Bobzien en un trabajo reciente. ${ }^{22}$ Como en el caso de los

${ }^{21}$ Cf. Williamson, 1994, pp. 8-35, especialmente, pp. 12-27.

22 Cf. Bobzien, 2002. Cf. Konstan, 1987, pp. 27-28. Según Konstan, ciertos filósofos helenísticos, incluyendo algunos estoicos, ya habían reconocido la existencia de objetos vagos en este sentido: "[...] according to certain schools, apparently including the Stoics and one faction among the skeptics (and also Epicureans and certain medical writers, if their references to atoms and pores are any evidence on this score), there exists a class of non-evident things such that it is not the case that we simply do not know, or do not yet know, whether the predicate $F$ or $-\mathrm{F}$ applies to them, but rather such that it is true that we can apply neither $\mathrm{F}$ nor -F [...] all the examples of this class of phenomena involve very large numbers of things, and, more specifically, the fact that a certain pair of contradictory attributes 
sofismas mentirosos, los sofismas montones constituirían casos especiales en que es necesario abandonar el principio de bivalencia: así como los estoicos, y tal vez el propio Crisipo, habría sostenido que proposiciones autoreferenciales como Miento carecen de un valor de verdad, así también - sostiene Bobzien - Crisipo habría afirmado que proposiciones que involucran el uso de predicados como Ser pocos carecen de valor de verdad en algunos casos límite. Esta interpretación es metafísica porque supone que, en realidad, existen objetos vagos en el sentido de que hay objetos que son neutrales respecto de ciertos predicados: no satisfacen ni estos predicados ni su negación. Según esta lectura, la solución que los estoicos habrían aportado a los sofismas montones habría consistido en simplemente suspender el juicio o "guardar silencio" tal como lo sugiere el texto 10. Sabiendo que cierto objeto $x$ es neutral respecto de cierto predicado $\mathrm{P}$ y su negación no-P (por ejemplo, sabiendo que 5 no es ni poco ni mucho), el sabio estoico no debe de asentir ni a la proposición $P x$ (cinco es poco) ni a la proposición no-Px (cinco es mucho). ${ }^{23}$

Cabe notar que un texto sobre el cual pretende apoyarse la interpretación epistemicista de los estoicos puede leerse de tal modo que también sirva de punto de apoyo para la interpretación metafísica. Se trata de 7 y, en particular, de la parte en que se afirma lo siguiente:

Pues en el caso del sorites, cuando la última presentación cognitiva es adyacente a la primera presentación no cognitiva y es

\footnotetext{
- oddness and evenness - that are predicable of ordinary quantities are neither of them predicable in the case of the number of stars or of the hairs in one's head". La evidencia que Konstan cita a favor de esta tesis (cf. 1987, pp. 18-32) proviene principalmente de Sexto Empírico (PH 2.97 M 7.243, 7. 393, 8. 25, 8. 147, 8.318 y 11.59) y Plutarco, Comm. not. 1079E-1080D). Sobre este tema y, en particular, la discusión de Crisipo sobre el dilema del cono según Plutarco, Comm. not. 1079E1080D, cf. Hahm, 1972.

${ }^{23}$ Sobre la estrategia descrita aquí de guardar silencio, cf. Sexto Empírico, $P H$ 2.253 y Cicerón, Acad. 2.93 con comentario en Bobzien, 2002, pp. 228-230, y Long \& Sedley, 1987, vol. 1, p. 230.
} 
casi indistinguible [de ella], los que están con Crisipo sostienen que, en el caso de presentaciones en las que hay una diferencia tan pequeña, el sabio se detendrá y guardará silencio, pero en aquellos casos en los que [tal diferencia] es más grande prestará asentimiento a aquélla como verdadera. ${ }^{24}$

Una lectura de este texto es que, si bien no hay objetos vagos, nuestras presentaciones no nos permiten distinguir entre casos límite: el problema de la vaguedad es epistemológico y debido a una insuficiencia nuestra para discriminar ciertas diferencias reales. Ésta es la lectura epistemicista de 7. Pero el texto también pueden entenderse en el sentido de que la diferencia entre presentaciones, por ser demasiado pequeña, es un indicio de que no existe realmente una diferencia tajante entre casos límite. Por ejemplo, en la serie de uno a diez, no existe un punto absoluto antes del cual se aplica el predicado Son pocos y después del cual se aplica Son muchos, sino que hay objetos en esa serie - problamente situados hacia la mitad - respecto de los cuales está objetivamente indeterminado si son pocos o son muchos. ${ }^{25}$ Esta divergencia entre dos lecturas igualmente razonables, pero opuestas, de 7 indica que este testimonio de Diógenes Laercio no permite, por sí solo, determinar cuál es la postura de la teoría estoica de los sofismas respecto del problema metafísico de si existen o no objetos vagos. ${ }^{26}$

Para concluir: ¿cómo se sitúan los estoicos respecto de la postura que adoptan los filósofos contemporáneos de la lógica sobre el problema de la vaguedad? Si la lectura realista de los estoicos es la correcta, hay una diferencia importante entre ellos y la postura predominante en la actualidad. De acuerdo con ésta, que podríamos calificar de "semanticista", el fenó-

\footnotetext{
${ }^{24}$ Texto citado tanto en Williamson, 1994, p. 18, como en Bobzien, 2002, p. 234.

${ }^{25}$ Cf. Bobzien, 2002, pp. 233-237.

${ }^{26}$ Como bien lo ha señalado Konstan, pruebas claras de que los estoicos reconocieron la existencia de objetos vagos pueden hallarse en otras fuentes, a las cuales ya me he referido en la n. 22 .
} 
meno de la vaguedad se debe a los significados del lenguaje y no al mundo extra-lingüístico: hay predicados lingüísticos cuyo significado no es del todo preciso, de tal manera que su dominio se traslapa en ciertos casos con el de su negación. Por ejemplo, "calvo" y "no-calvo", en virtud de una imprecisión de significado, pueden ambos predicarse correctamente de un cierto número de casos. ${ }^{27} \mathrm{El}$ semanticismo se aparta del epistemicismo en la medida en que el primero atribuye la vaguedad a una imprecisión semántica del lenguaje, mientras que el segundo a una carencia de nuestro aparato cognoscitivo. Pero el semanticismo también se aparta del realismo en la medida en que el realismo atribuye la vaguedad a ciertos rasgos del mundo extra-lingüístico y no a una imperfección semántica del lenguaje. De acuerdo con el realismo, existen objetos vagos en el sentido en que hay predicados tales que ni ellos ni su negación se predican de estos objetos. Para regresar a un ejemplo anterior, en la serie numérica de 1 a 10, suponiendo que 10 es mucho y 1 es poco, habría números intermedios que no son ni poco ni mucho. Como puede apreciarse a través de estos dos ejemplos, las dos teorías, además de diferenciarse por atribuir la vaguedad a cosas distintas (al lenguaje en un caso y al mundo extra-lingüístico en el otro), también difieren entre sí en virtud de querer explicar fenónemos distintos relacionados con la vaguedad: (a) el que haya predicados tales que ellos y su negación pueden, en ciertos casos, aplicarse a los mismos objetos ("calvo" y "no-calvo") y (b) el que haya predicados tales que ellos y su negación no se aplican a ningún objeto de un cierto dominio. El semanticismo contemporáneo se centra en el primer fenómeno y lo atribuye a una imprecisión en el significado de los predicados lingüísticos; el estoicismo, en cambio, se refiere al segundo fenómeno y lo

${ }^{27}$ Cf. Sainsbury, 2009, pp. 24-25 y 47-49, aunque ciertos filósofos contemporáneos de la lógica rechazan el semanticismo, entre ellos, Evans, 1978, y Wiggins, 2001, pp. 161-171. 
atribuye a una especie de neutralidad en los objetos mismos respecto de ciertos predicados y sus negaciones, pues no satisfacen ni los unos ni los otros y, por ello, son "vagos" en el sentido de que son neutrales a este respecto. Ésta es sin duda una razón por la cual los estoicos, a diferencia de la mayoría de los filósofos modernos de la lógica, son realistas respeto de la vaguedad. Ahora bien, ¿hay alguna prueba de que los estoicos tenían cuando menos conocimiento del primer problema? Dejaremos esta pregunta abierta limitándonos a observar que, si bien en una fuente antigua se menciona el ejemplo del hombre "calvo", 28 no es del todo claro lo siguiente: (a) si se refiere a un ejemplo estoico $\mathrm{y}$, tampoco, (b) si pretende ejemplificar el primer problema o sólo una versión del segundo (ciertos hombres no son ni "calvos" ni "no calvos").

${ }^{28}$ Cf. Galeno, Exp. Med. xx. 3 citado en Barnes-Bobzien-Mignucci, 1999, p. 170. 
Apéndice

Ediciones consultadas

- Diógenes Laercio: H. S. Long (ed.), Diogenis Laertii vitae philosophorum, 2 vols., Oxford, Clarendon Press, 1964.

- Luciano de Samosata: A. M. Harmon (ed.), Lucian, vol. 2., Cambridge, Mass., Harvard University Press, 1915.

- Sexto Empírico: H. Mutschmann (ed.), Sexti Empirici opera, vol. 1, Leipzig, Teubner, 1912.

- Plutarco, Moralia: R. Westman \& M. Pohlenz (edd.), Plutarchi moralia, vol. 6.2, Leipzig, Teubner, $1959^{2}$.

- Simplicio (texto 6): H. Diels (ed.), Simplicii in Aristotelis physicorum libros octo commentaria, 2 vols. (Commentaria in Aristotelem Graeca 9 \& 10, Berlin, Reimer, 9, 1882; 10, 1895).

- Simplicio (texto 10) K. Kalbfleisch, Simplicii in Aristotelis categorias commentarium (Commentaria in Aristotelem Graeca 8, Berlin, Reimer, 1907).

- Galeno: K. Gabler (ed.), Libellus de captionibus quae per dictionem fiunt ad fidem unius qui superest codicis editus [Dissertatio inauguralis], Rostock, 1903.

- Cicerón: Harris Rackham (ed.), en Loeb Classical Library.

A continuación cito in extenso los pasajes a los que me refiero en este artículo. A excepción de los textos 4 y 7 , los demás no están acompañados de un aparato crítico y, por ende, no se toman en cuenta otras lecturas que pudieran afectar el significado filosófico de los textos.

1a Diógenes Laercio 7.43-44

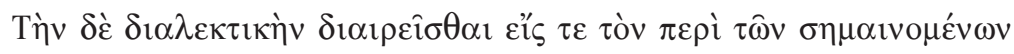

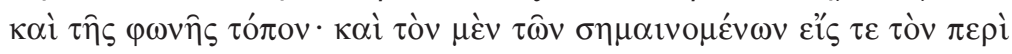

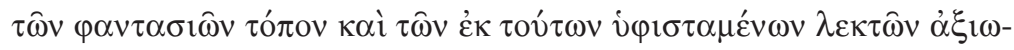




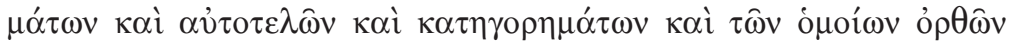

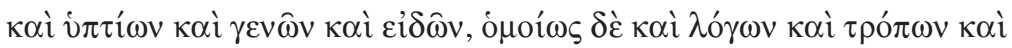

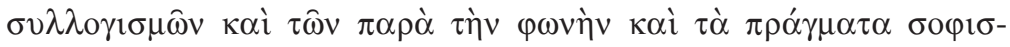

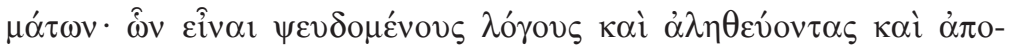

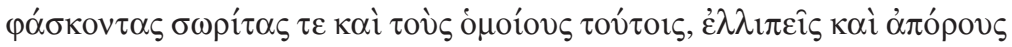

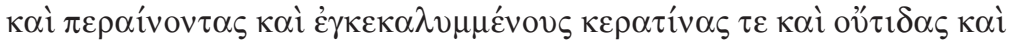

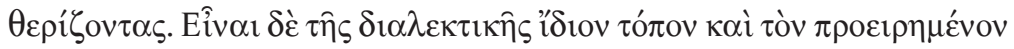

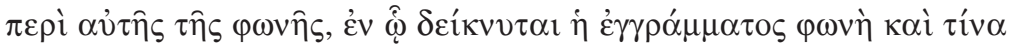

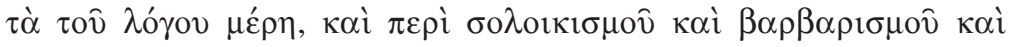

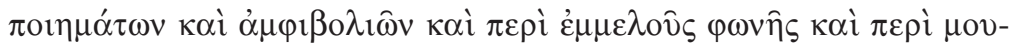

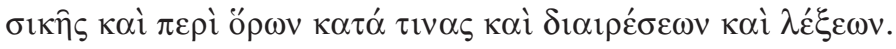

La dialéctica se divide en un área concerniente a los significados y otra al sonido vocal; y el [área] de los significados [se divide] en área de las presentaciones y de los decibles que a partir de ellas subsisten: proposiciones, [que son decibles] completos, predicados - tanto activos como pasivos - , géneros y especies $y$, de manera similar, argumentos, modos de argumento, silogismos y sofismas que dependen del sonido vocal y de los estados de cosas. Entre esos sofismas se encuentran los argumentos "del mentiroso", "del que dice la verdad", "del que niega los argumentos", "del sorites" y, los defectuosos, aporéticos y los conclusivos, que se asemejan a ellos. Los argumentos "del velo", "del cornudo", "del no-alguien" y "del segador". Corresponde también a la dialéctica el área peculiar, antes mencionada, que se refiere al sonido vocal mismo, en la cual se muestra la expresión escrita y cuáles son las partes del discurso, la cual se refiere al solecismo, al barbarismo, la poesía, la ambigüedad, la expresión melodiosa, la música, y, de acuerdo con algunos [estoicos], a las definiciones, las divisiones y las expresiones.

\section{1b Sexto Empírico PH 2.229-231}

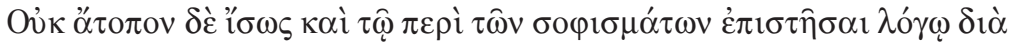

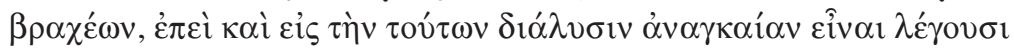

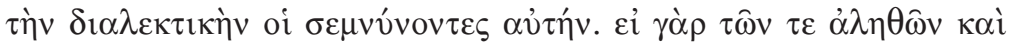

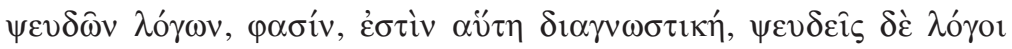

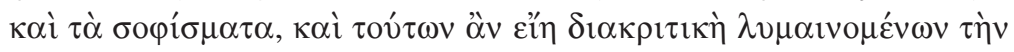




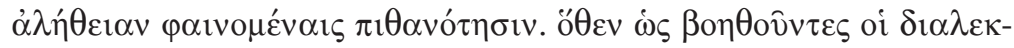

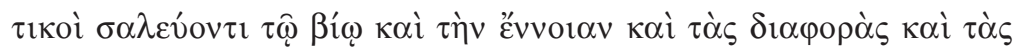

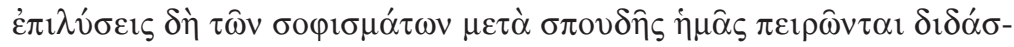

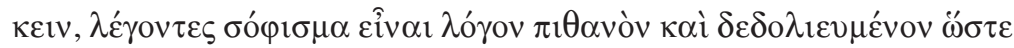

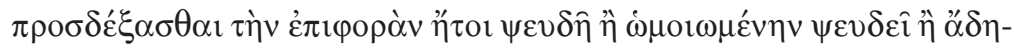

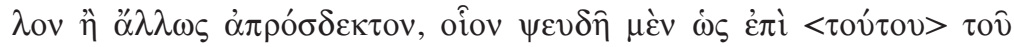

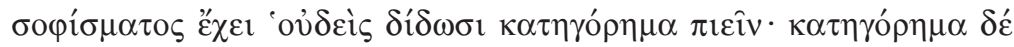

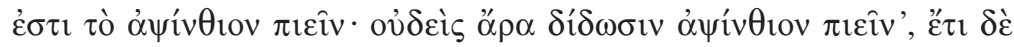

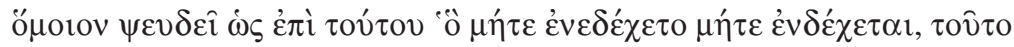

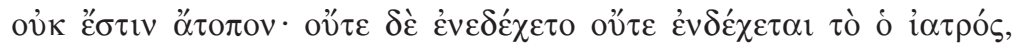

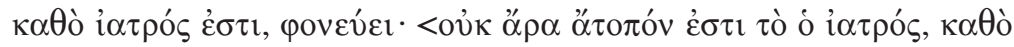

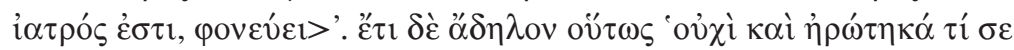

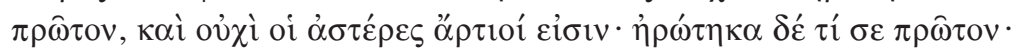

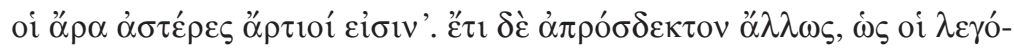

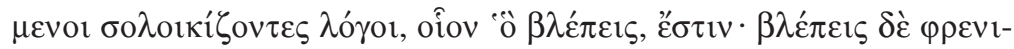

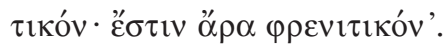

Con probabilidad no esté fuera de lugar enfocarnos brevemente en la teoría de los sofismas, pues quienes veneran la dialéctica misma dicen que también es necesaria para la solución de éstos. En efecto, afirman, si ésta es capaz de identificar argumentos verdaderos y falsos, y los sofismas también son argumentos falsos, también debe ser capaz de distinguirlos a ellos, que ultrajan la verdad por medio de su aparente verosimilitud. Por ello, los dialécticos, saliendo al rescate de nuestra vacilante vida, intentan con empeño enseñarnos la concepción de los sofismas, sus diferencias y sus soluciones, al decir que un sofisma es un argumento convincente, pero, un hecho engañoso, de tal modo que es aceptada su conclusión, que es falsa o igual a una falsa o no-evidente o de otra forma inaceptable. Por ejemplo, es falsa como en el caso de este sofisma: "nadie da a beber un predicado; pero beber ajenjo es un predicado; por lo tanto, nadie da a beber ajenjo". En cambio, [la conclusión] es igual a una falsa como en éste: "aquello que ni era ni es el caso, no es absurdo; pero ni era ni es el caso que el médico en cuanto médico cometa un asesinato; <por lo tanto, no es absurdo que el médico en cuanto médico cometa un asesinato>". Por otra parte, [la conclusión] es no manifiesta de este modo: "no ambas son el caso: te he hecho una primera pregunta y no es par el número de estrellas; pero te he hecho 
una primera pregunta: por lo tanto, el número de estrellas es par". Y [la conclusión] es de otra forma inaceptable como en los argumentos que enuncian solecismos, por ejemplo: "lo que ves existe; pero ves una alucinación; por lo tanto, la alucinación existe".

\section{1c Diógenes Laercio 7.79}

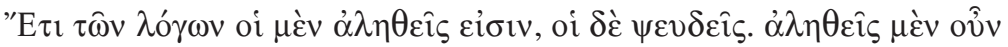

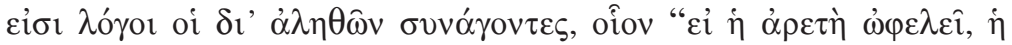

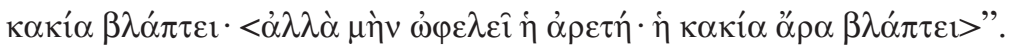

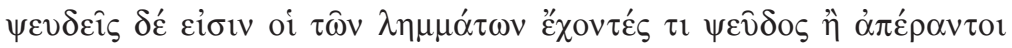

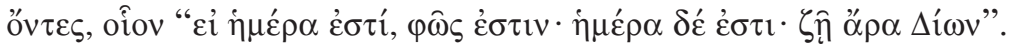

Además, de los argumentos, algunos son verdaderos, otros, falsos. Verdaderos son los argumentos que concluyen a través de [premisas] verdaderas, por ejemplo: "si la virtud beneficia, el vicio daña"; [pero por cierto la virtud beneficia; por lo tanto, el vicio daña]. Falsos son los argumentos que poseen una de sus premisas falsa o son inválidos, por ejemplo: "si es de día, hay luz; es de día; por lo tanto, Dión vive”.

2 Luciano, Vit. auc. 22

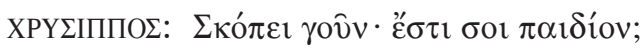

АГОРАЕТН $\Sigma:$ Tí $\mu$ v́v;

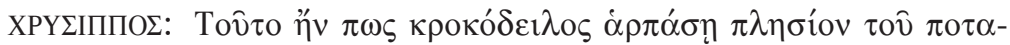

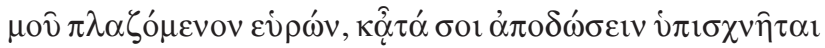

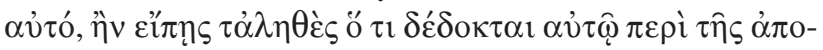

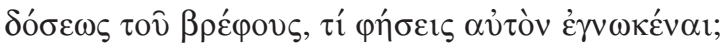

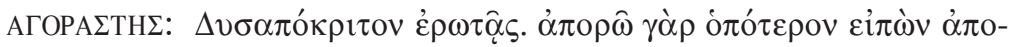

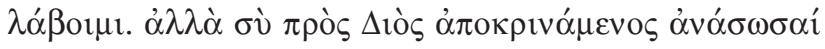

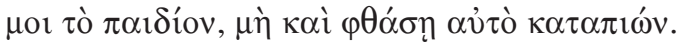

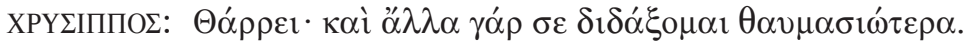

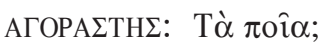

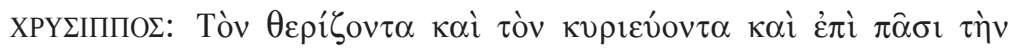
'H 


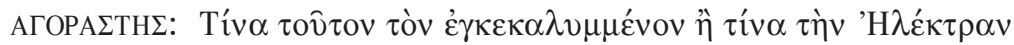
$\lambda \varepsilon ́ \gamma \varepsilon 1 \zeta ;$

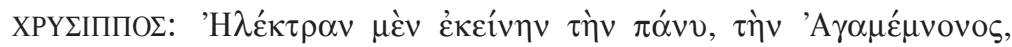

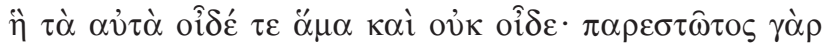

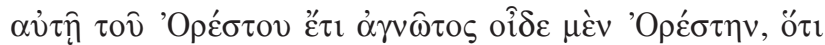

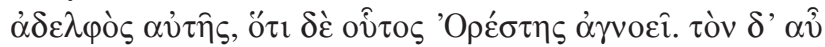

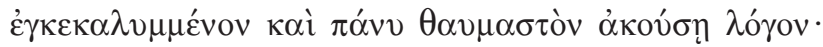

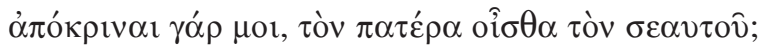

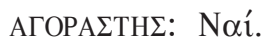

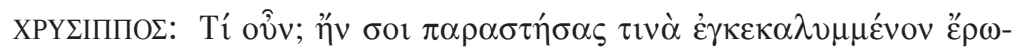

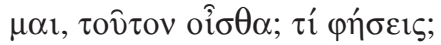

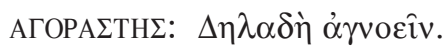

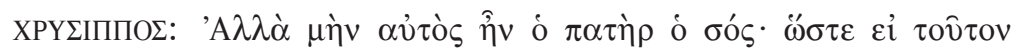

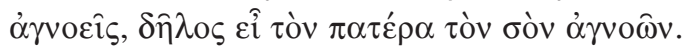

CRISIPO: Pero mira: ¿tienes un niño?

COMPRADOR: ¿Y qué?

CRISIPO: Si al encontrarlo paseando cerca del río, un cocodrilo de algún modo lo rapta y enseguida te promete entregarlo si dices con verdad lo que le parece a él respecto de la entrega del crío, ¿qué le dirás que sabes?

COMPRADOR: Preguntas algo difícil de responder, pues me confunde con cuál [de las respuestas], al pronunciarla, recobraría [a mi hijo]; tú, en cambio, ipor Zeus!, sálvame al niño respondiendo [la pregunta con verdad], para que [el cocodrilo] no se precipite tragándoselo.

CRISIPO: No temas, pues habré de enseñarte otras cosas aún más sorprendentes.

COMPRADOR: ¿Cuáles son?

CRISIPO: "El Segador", "el Maestro" y, sobre todo, "la Electra", es decir, "el Encapuchado".

COMPRADOR: ¿Cuál es "el Encapuchado" y cuál es "la Electra”?

CRISIPO: Electra es aquella famosa, la de Agamenón, la cual conoce y al mismo tiempo no conoce las mismas cosas. En efecto, al ponerse Orestes junta a ella sin aún darse a conocer, ella conoce a Orestes, porque es su hermano, pero ignora que éste es Orestes. Tam- 
bién escucharás "el Encapuchado", un argumento sumamente sorprendente. Respóndeme: ¿conoces a tu propio padre?

COMPRADOR: Sí.

CRISIPO: Pues bien: si habiendo colocado frente a ti a alguien encapuchado, [te] pregunto si lo conoces, ¿qué [me] dirás?

COMPRADOR: Obviamente que ignoro [quién es].

CRISIPO: Sin embargo, esta misma persona era tu padre. Por consiguiente, si ignoras quién es, es claro que ignoras quién es tu padre.

\section{Diógenes Laercio 7.186-187}

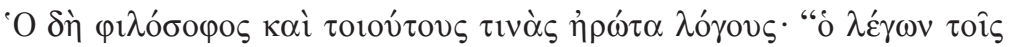

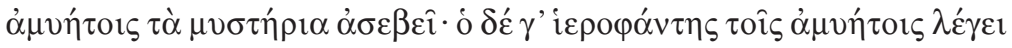

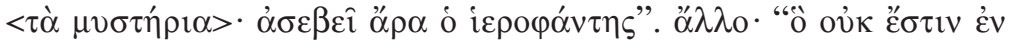

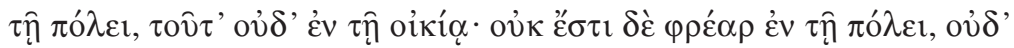

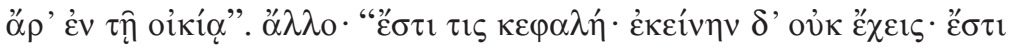

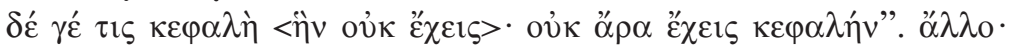

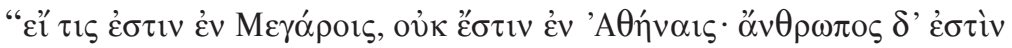

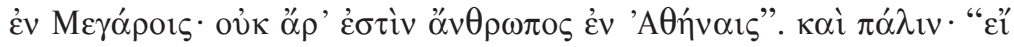

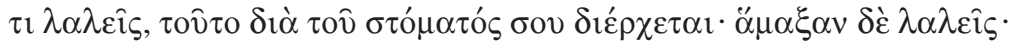

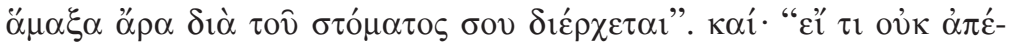

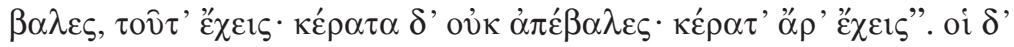

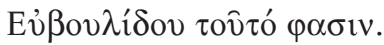

[Crisipo] el filósofo también ponía a consideración argumentos como los siguientes: "quien divulga los misterios a los no-iniciados es impío; pero el hierofante, al menos, divulga <los misterios $>$ a los no-iniciados; por consiguiente, el hierofante es impío". Otro más: "lo que no está en la ciudad, tampoco está en la casa; no hay un pozo en la ciudad; por consiguiente, tampoco hay uno en la casa". Otro más: "existe cierta cabeza, pero no la tienes; pues bien, existe una cabeza que no tienes; por consiguiente, no tienes una cabeza". Otro más: "Si alguien está en Megara, no está en Atenas; pero un hombre está en Megara; por consiguiente, un 
hombre no está en Atenas". De nuevo: "si pronuncias algo, eso pasa por tu boca; pronuncias carro; por consiguiente, un carro pasa por tu boca" y "si no has perdido algo, lo tienes; no has perdido unos cuernos; por lo tanto, tienes unos cuernos". Otros dicen que éste es de Eubúlides.

\section{Cicerón, Acad. 2.95}

nempe fundamentum dialecticae est quidquid enuntietur (id autem appellant $\dot{\alpha} \xi i \omega \mu \alpha$, quod est quasi effatum) aut verum esse aut falsum. quid igitur haec vera an falsa sunt: "si te mentiri dicis idque verum dicis, mentiris $<*>$ verum dicis"? Haec scilicet inexplicabilia esse dicitis, quod est odiosius quam illa quae nos non comprehensa et non percepta dicimus. Sed hoc omitto, illud quaero: si ista explicari non possunt nec eorum ullum iudicium invenitur ut respondere possitis verane an false sint, ubi est illa definitio, effatum esse id quod aut verum aut falsum sit?

mentiris $\left.<^{*}\right\rangle$ verum dicis lac. ind. edd. : [idque verum dicis], mentiris $<e t>$ verum dicis Plasberg : mentiris <an> verum dicis Schütz : mentiris <et, si te mentiri dicis, idque mentiris $>$ verum dicis Hülser : mentiris <et, si mentiris,> verum dicis Mignucci : mentiris <et> verum dicis Barnes-Bobzien-Mignucci

Claramente es fundamento de la dialéctica que aquello que se enuncia (a esto lo llaman axíoma, es decir, proposición) es o bien verdadero o bien falso. Pues bien ¿qué son éstas [sc. proposiciones], verdaderas o falsas: "si dices que mientes y en esto dices la verdad, mientes $<y$, si mientes, > dices la verdad"? Ustedes dicen que son inexplicables, lo cual es aún más repugnante que aquellas que decimos que no comprendemos y no percibimos. Pero dejo esto de lado y [me] pregunto lo siguiente: si éstas [sc. proposiciones] no pueden explicarse y ningún juicio respecto de ellas se descubre que les permita a ustedes responder si son verdaderas o falsas, ¿dónde está aquella definición, según la cual [una proposición] es aquello que o bien es verdadero o bien es falso? 


\section{Plutarco CN 1059D-E}

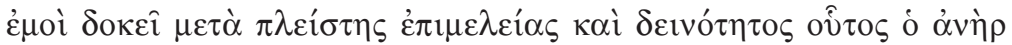

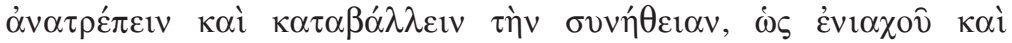

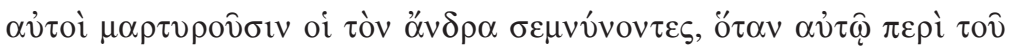

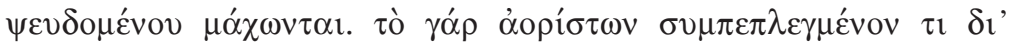

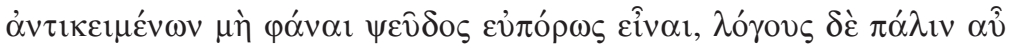

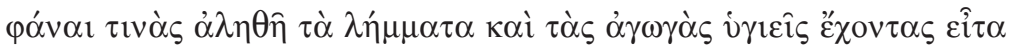

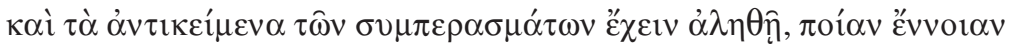

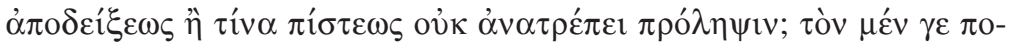

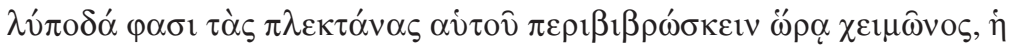
$\delta \varepsilon \grave{\varepsilon}$ X

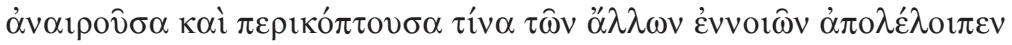

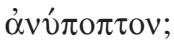

Este hombre me parece echar abajo y hundir la costumbre con gran ahínco y destreza como ocasionalmente lo testifican los que lo veneran, cada vez que se enfrentan con él respecto del "Mentiroso". En efecto, ¿a qué clase de concepción de demostración o de preconcepción de prueba no derriba el negar que es falsa sin restricción una conjunción que se obtiene por medio de [proposiciones] contradictorias indefinidas $\mathrm{y}$, asimismo, afirmar que en ciertos argumentos que poseen premisas verdaderas y [llevan a cabo] una inferencia congruente, las contradictorias de sus conclusiones también son verdaderas? En todo caso, dicen que el pulpo carcome sus propios tentáculos en la época de invierno, pero la dialéctica de Crisipo, al destruir y amputarse sus principales partes y principios, ¿a cuál de las demás concepciones ha dejado fuera de sospecha?

6 Simplicio, in Phys. 1299, 35-1300, 10

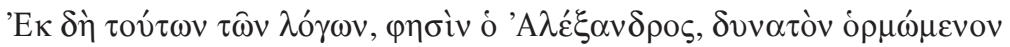

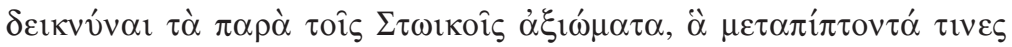

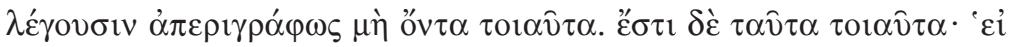

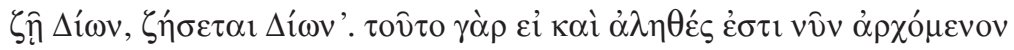

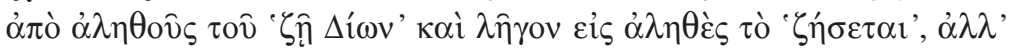

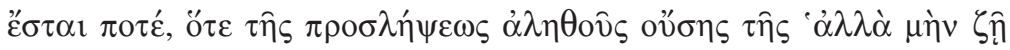




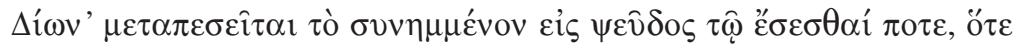

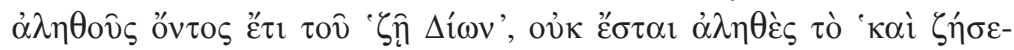

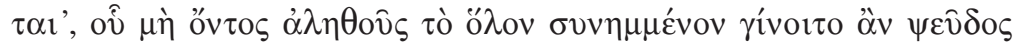

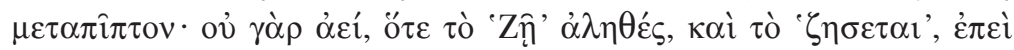

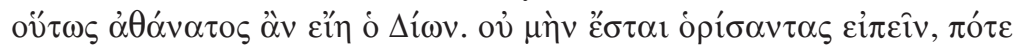

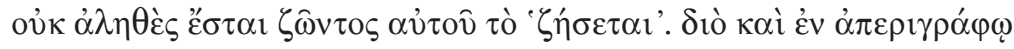

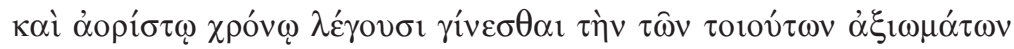
$\mu \varepsilon \tau \alpha \dot{\alpha} \pi \tau \omega \sigma i v$.

Comenzando a partir de estos argumentos, dice Alejandro [de Afrodisia], es posible mostrar que, en los estoicos, las proposiciones que algunos llaman "cambiantes de forma indeterminada" no son tales. Éstas son de este tipo: "Si Dión está vivo, Dión estará vivo", pues si bien esto es verdadero ahora (teniendo como antecedente la proposición verdadera "Dión está vivo" y como consecuente verdadero "estará vivo"), sin embargo, llegará un momento en que, siendo verdadera la premisa adicional "pero Dión está vivo", el condicional cambiará [de valor de verdad] a falso, en virtud de que llegará un momento en que, siendo todavía verdadera "Dión vive" [ya] no será verdadera "y estará vivo": al no ser ésta verdadera, el condicional en su conjunto, al ser cambiante, se volvería falso. En efecto, no siempre [es verdadera] "estará vivo" cuando "está vivo" es verdadera, pues de ese modo Dión sería inmortal. Pero, por cierto, no será posible decir definidamente cuándo, al estar vivo él, no será verdadera "estará vivo". Por ello, dicen que el cambio [de valor de verdad] de tales proposiciones ocurre en un tiempo indefinido e indeterminado.

\section{Diógenes Laercio 7.82}

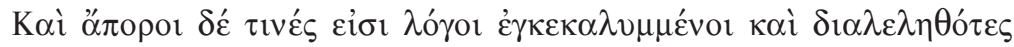

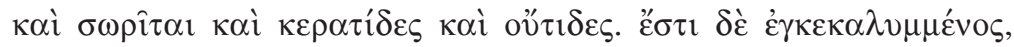

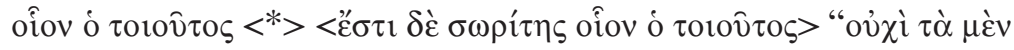

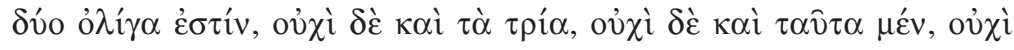

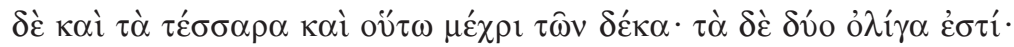

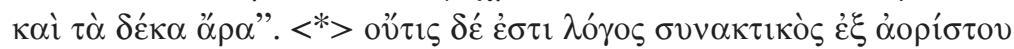

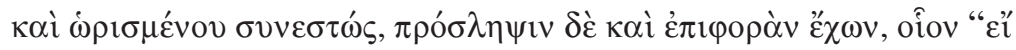




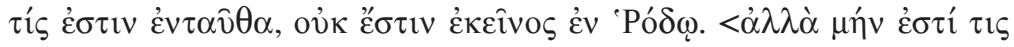

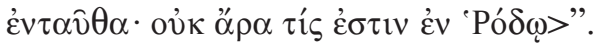

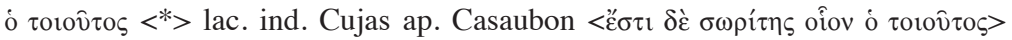

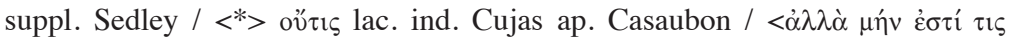

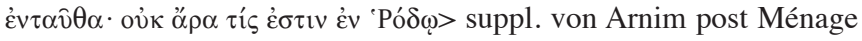

También hay algunos argumentos aporéticos: "los encapuchados", "los ocultos", "los montones", "los cornudos" y "los noalguien". "El encapuchado" es como éste $\left.<^{*}\right\rangle$. $<$ "El montón" es como éste:> no es el caso que "dos" sean pocos, pero que "tres" no lo sean, ni que éstos [lo sean] pero "cuatro" no lo sean, y así hasta llegar a "diez". Sin embargo, dos son pocos, por consiguiente también lo son "diez". $<*>$ "El no-alguien" es un argumento concluyente que, al tener una premisa adicional y una conclusión, está formado por una proposición indefinida y una definida [como primera premisa], por ejemplo, "si hay una persona aquí, ésta no está en Rodas. <Pero hay una persona aquí; por consiguiente, no hay una persona en Rodas. $>$

\section{Diógenes Laercio 7.62}

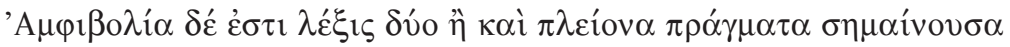

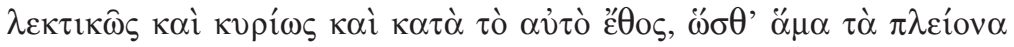

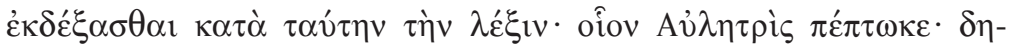

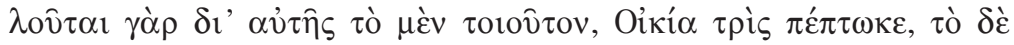

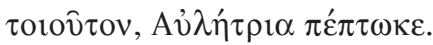

Una ambigüiedad es una expresión que, lingüística y estrictamente, significa dos o incluso más estados de cosas y de acuerdo con el mismo uso, de manera que, conforme a esa expresión, se admiten simultáneamente los múltiples [significados]. Por ejemplo, auletris peptoke pues por sí misma [esta expresión en griego] revela lo siguiente: "una casa tres veces se ha caído" o "Una flautista se ha caído". 
9 Galeno, Soph. 595, 8-596, 15

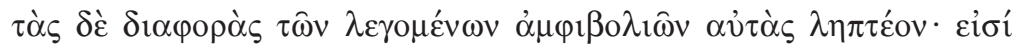

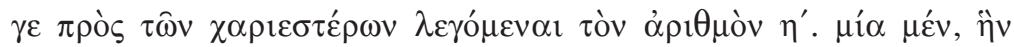

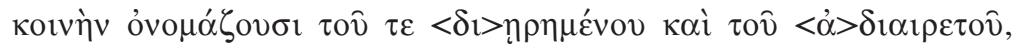

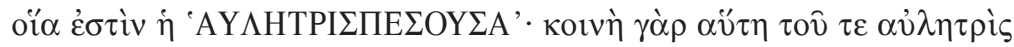

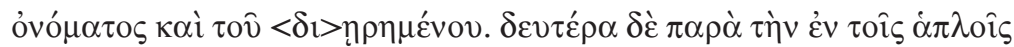

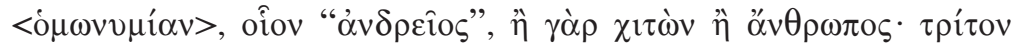

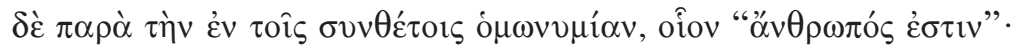

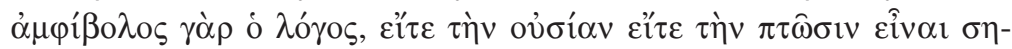

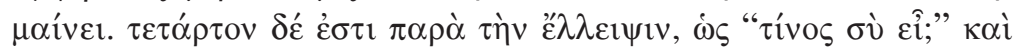

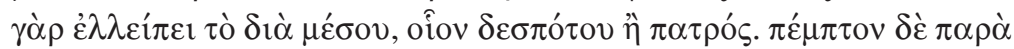

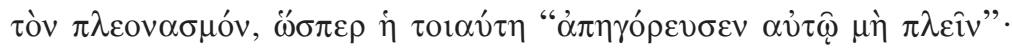

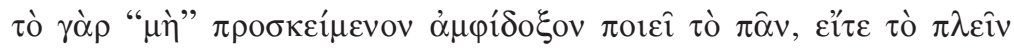

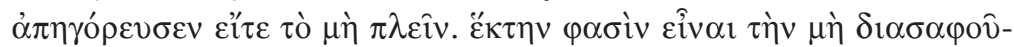

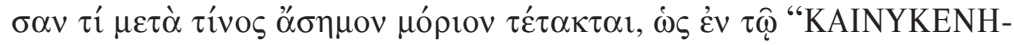

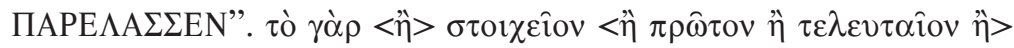

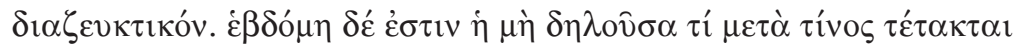

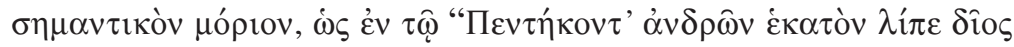

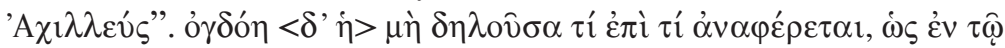

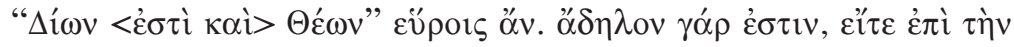

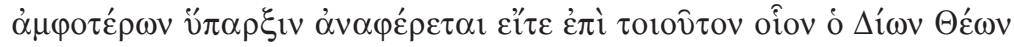
$\dot{\varepsilon} \sigma \tau i v \hat{\eta} \pi \alpha ́ \lambda$ เv.

Deben tomarse en cuenta las mismas diferencias entre las llamadas "ambigüedades". En todo caso, se enuncian ocho por parte de los [estoicos] más agudos. Una primera es la que llaman común al [nombre] dividido y al indivisible, tal como la [ambigüedad] "AULETRISPESOUSA", pues es común al nombre "auletris" [en la oración "auletris pesousa": "la flautista que cayó"] y al nombre dividido [sc. "aule tris" en la oración "aule tris pesousa": "una casa que cayó tres veces"]. Una segunda se da respecto de la <homonimia $>$ en [nombres] simples, por ejemplo "masculino", pues [masculino] es abrigo u hombre. Una tercera se da respecto de la homonimia en [nombres] compuestos, por ejemplo, "es hombre", pues es ambiguo si la expresión significa la substancia o el caso nominativo. Una cuarta se da respecto de la omisión como "de quién eres?", pues se omite el término medio, por ejemplo, "del amo" o "del padre". Una quinta se da respecto 
del pleonasmo, como la de este tipo: "le prohibió no velear". En efecto, la palabra "no", al agregarse, hace que el todo tenga un doble sentido respecto de si [el hablante] le prohibió velear o no velear. Dicen que una sexta es la que no dejó claro qué parte asemántica se construye con cuál, como en la [expresión] "KAINUKENHPARELASSEN". En efecto, la letra < $H$ "> es $<$ o bien primera, o final, o $>$ disyuntiva. Una séptima es la que no muestra qué parte semántica se construye con cuál, como en la [expresión]: "a cincuenta de cien hombres dejó el 'noble' Aquiles". Una octava es la que no muestra qué se refiere a qué, como podrías encontrarla en la <expresión> "Dión es también Teón", pues no es patente si se refiere a la existencia de ambos [sc. Dión es y también Teón, es decir, ambos existen] o a algo tal como "Dión es Teón" y al revés [es decir, existe una identidad entre ambos: son la misma persona].

10 Simplicio, in Cat. 24, 9-21

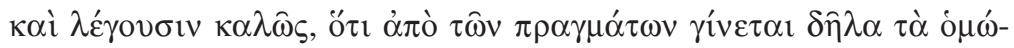

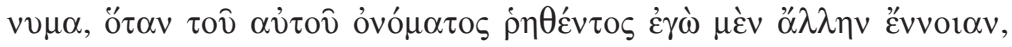

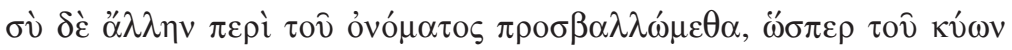

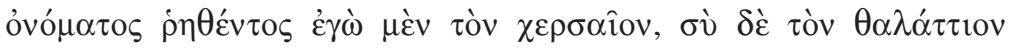

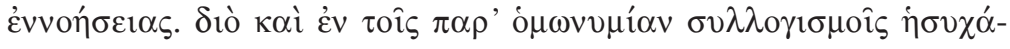

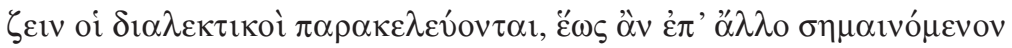

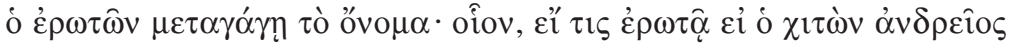

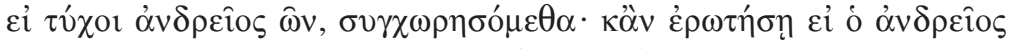

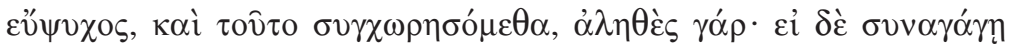

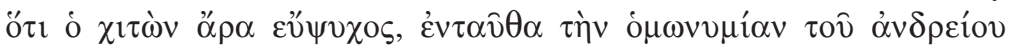

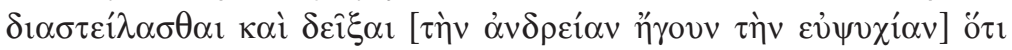

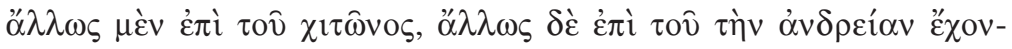
$\tau$

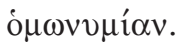

$\mathrm{Y}$ argumentan correctamente [al decir] que las homonimias manifiestas proceden de las cosas cada vez que, al pronunciarse el mismo nombre, proponemos, yo, una concepción y tú, otra, respecto del nombre, como cuando al haberse pronunciado el nombre "perro" yo pensé, por mi parte, en el perro terrestre, pero tú, 
en el perro marino. Por ello, en los silogismos que descansan sobre una homonimia, los dialécticos nos sugieren callar hasta que la persona que pregunta remita la palabra a otro referente. Por ejemplo, si alguien pregunta si "el abrigo" es masculino, concordaremos (si resultara que es masculino). Y si preguntara si "el masculino" es animoso, también concordaremos, pues es cierto. En cambio, si dedujera que, por lo tanto, "el abrigo" es animoso, en esa circunstancia recomiendan distinguir la homonimia de "masculino" y mostrar que se predica de una manera del abrigo y de otra distinta de quien tiene valentía. Por consiguiente, en sentido estricto, [son] los estados de cosas, pero no los nombres, los que producen la homonimia.

\section{Plutarco, Comm. Not. 1084C-D}

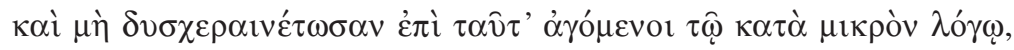

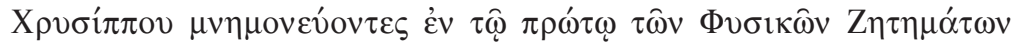

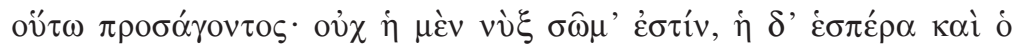

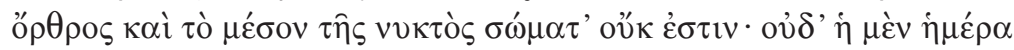

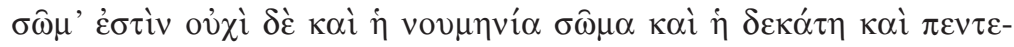

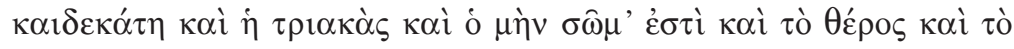
$\varphi \theta$ tvó

Y que ustedes no se disgusten si son conducidos por el argumento que [avanza] poco a poco hacia esos casos, acordándonos de Crisipo que en el libro I de sus Investigaciones Físicas concluye así: no es el caso que la noche sea un cuerpo, y la tarde, el alba y la medianoche no sean cuerpos; tampoco es el caso que el día sea un cuerpo, pero que no sea un cuerpo el primer día del mes, el décimo, el quinceavo, el trigésimo, el mes [entero], el verano, el otoño y el año. 


\section{BIBLIOGRAFÍA}

Atherton, Catherine, The Stoics on Ambiguity, Cambridge, Cambridge University Press, 1993.

BARNES, Jonathan, "La doctrine du retour éternel", en J. Brunschwig (ed.), Les Stö̈ciens et leur logique, Paris, Vrin, 1978.

-, Susanne Bobzien y Mario Mignucci, "Chapter 5: Logic", en Keimpe Algra, Jonathan Barnes, Jaap Mansfeld, Malcolm Schofield (eds.), The Cambridge History of Hellenistic Philosophy, Cambridge, Cambridge University Press, 1999.

Beall, Jeffrey (ed.), Liars and Heaps. New Essays on the Paradox, Oxford, Oxford University Press, 2003.

- (ed.), Revenge of the Liar. New Essays on the Paradox, Oxford, Oxford University Press, 2007.

BobZien, Susanne, "Chrysippus and the epistemic theory of vagueness", Proceedings of the Aristotelian Society, 102, 2002, pp. 217-238.

BoERI, Marcelo, "Incorpóreos, tiempo e individuación en el estoicismo. A propósito de 'Tiempos, objetos y sucesos en la metafísica estoica' de Ricardo Salles", Diánoia, 51, 2003, pp. 181-193.

CAnto, Monique, "Introduction", Platon. Euthydème, Paris, GarnierFlammarion, 1989.

DE RIJK, Lambertus Marie, "Some Notes on the Mediaeval Tract De insolubilibus, with the Edition of a Tract Dating from the End of the Twelfth Century", Vivarium, 4, 1966, pp. 83-115.

Dufour, Richard, Chrysippe. Oeuvre Philosophique, Paris, Les Belles Lettres, 2004.

Evans, Gareth, "Can there be vague Objects?", Analysis, 38, 1978, p. 208.

Hahm, David, "Chrysippus'Solution to the Democritean Dilemma of the Cone", Isis, 63, 1972, pp. 205-220.

Konstan, David, "Points, lines and infinity: Aristotle's Physics Zeta and Hellenistic Philosophy", en John J. Cleary (ed.), Proceedings of the Boston Area Colloquium in Ancient Philosophy, 3, 1987, pp. 1-32.

Long, Anthony, David Sedley, The Hellenistic Philosophers, Cambridge, Cambridge University Press, 1987.

Mates, Benson, Stoic Logic, Berkeley, University of California Press, 1953. Praechter, Karl, "Platon und Euthydemus", Philologus, 87, 1932, pp. 121-135.

SAinsbury, Mark, Paradoxes (3a. ed.), Cambridge, Cambridge University Press, 2009.

SALLES, Ricardo, "Tiempos, objetos y sucesos en la metafísica estoica", Diánoia, 47, 2002, pp. 3-22. 
- , "On the Individuation of Times and Events in orthodox Stoicism", en Ricardo Salles (ed.), Metaphysics, Soul and Ethics. Themes from the work of Richard Sorabji, Oxford, Oxford University Press, 2005.

SEDLEY, David, "Diodorus Cronus", Stanford Encyclopedia of Philosophy, 2009. http://plato.stanford.edu/entries/diodorus-cronus/

Spade, P. V., Lies, Language and Logic in the Later Middle Age, London, Variorum Reprints, 1988.

-, "Ockham on Self-Reference", Notre Dame Journal of Formal Logic, 15, 1974, pp. 298-300. Reimp. en Spade 1988.

WigGins, David, Sameness and Substance Renewed, Cambridge, Cambridge University Press, 2001.

Williamson, Timothy, Vagueness, London, Routledge, 1994. 
